\title{
ASSESSMENT OF URBAN UTILITIES FOR MUMBAI CITY USING 3D MODELING TECHNIQUES
}

\author{
Shrenik Dinesh Shah \\ PG Student, Department of Civil Engineering, Pillai HOC College of Engineering \& \\ Technology, Rasayani, Maharashtra, India
}

Raju Narwade

Associate Professor, Department of Civil Engineering, Pillai HOC College of Engineering \& Technology, Rasayani, Maharashtra, India

\section{Karthik Nagarajan}

Associate Professor, Department of Civil Engineering, Pillai HOC College of Engineering \& Technology, Rasayani, Maharashtra, India

\begin{abstract}
In the early days, humans used to live in semi-permanent villages. They shift as soon as their land becomes less fertile. With the up-gradation in technology and the rise in the standard of living, people prefer settling in urban locations than living in rural areas. This urbanization leads to challenge in today's planning and development departments. The growth of the world population and migration of people are creating congestion in cities. The cities are now more crowded, dense with persistent traffic problems and a rise in pollution levels. There needs planning for adequate food, sanitation and education for all, and thereby making it necessary to plan for sustainability. Instead of separate residences, they will be constructed vertically. They may possess everything people need in their daily life. The future will see vertical farms and skyscrapers for food production and renewable sources for energy production. The generation of the $3 D$ city model will help in planning and analysis of the city. This helps in the development of small self-sustainable cities mainly focusing on local and sustainable production. We have worked on the Nariman Point, Mumbai in this paper. We have studied the buildings, congestion and land usage of this region and analyzed the current scenario of the region. The 3D modeling of the city will help the city and town planners to optimize the city.
\end{abstract}

Keywords: 3D Modeling, Town planning, Urbanization, City planning, Mumbai, India. 
Cite this Article: Shrenik Dinesh Shah, Raju Narwade and Karthik Nagarajan, Assessment of Urban Utilities for Mumbai City Using 3D Modeling Techniques. International Journal of Civil Engineering and Technology, 11(5), 2020, pp. 1-10. https://iaeme.com/Home/issue/IJCIET?Volume=11\&Issue=5

\section{INTRODUCTION}

A majority of world's population resides in city areas. The global population is around 7 billion and it will soon reach a 10 billion mark. This will have an adverse effect on our environment, due to the rise in population and will eventually cause a shortage of available resources. The world will be facing health issues due to the increase in pollution and overcrowding of localities. India is the home for approximately 1.3 billion people, ranking 2 nd in the world in terms of population. The population was never a problem in India, density is the real problem. India has the densest population in the world. The density of the population in India is 1,202 people per square mile which is very high when compared with the country having the largest population in the world, China has a density of only 397 people per square mile.

The graph (Figure 1) shows a representation of urban population growth with the rural population, it means there will be an expansion of population in the urban areas as compared to the rural areas. This will crowd the cities and towns adding economic and social crises

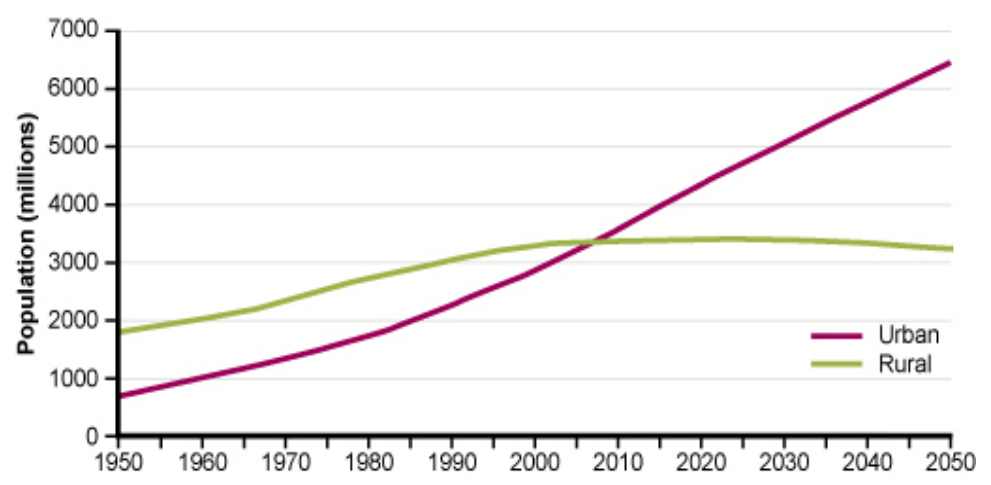

Figure 1 Urban and rural population of the world, 1950-2050. (Source: UNDESA, 2014)

This triggers the need for urban planning, social planning and organizing a city in a manner where we can fulfill the basic need of food supplies, sanitation and education for all. For an organized city planning and development, current data and analysis are required about the built-up area, floor space index of the region, the infrastructure of the region is required. $3 \mathrm{D}$ city modeling will ease the planners to develop the cities much more suitable to live.

In the last few years, 3D modeling based visualization has gained a lot of popularity, with a due course of time the solutions are now more economical and rapid. The reason for its marketability is its vast usage options. They can be used by students for the research purpose into the planning and design field but also for the gaming and the movie industry. The term modeling is drafting a 3D model by means algorithms and the given set of rules, thus let you generate a mega-size 3D model saving both time and money. 3D modeling has been mainly used for various types of 3D modeling projects which include architectural drawings, interior designs, landscaping, and game design and development. This can be used to develop a small self-sustainable city focusing on sustainable production. 


\section{OBJECTIVE}

The purpose of this study are as follows:

- To create the 3D model of Nariman Point Region, Mumbai for urban planning and development.

- To assess the urban utilities - land use of Nariman Point region of Mumbai city by using 3D modeling techniques.

\section{STUDY REGION}

Mumbai also known as "Bombay" or "Bambaye" is a city located in the state of Maharashtra, India. It has a geographic location which is surrounded by water bodies and oceans from three sides. This is the reason the area of this city is comparatively less and it does not have an option for further expansion.

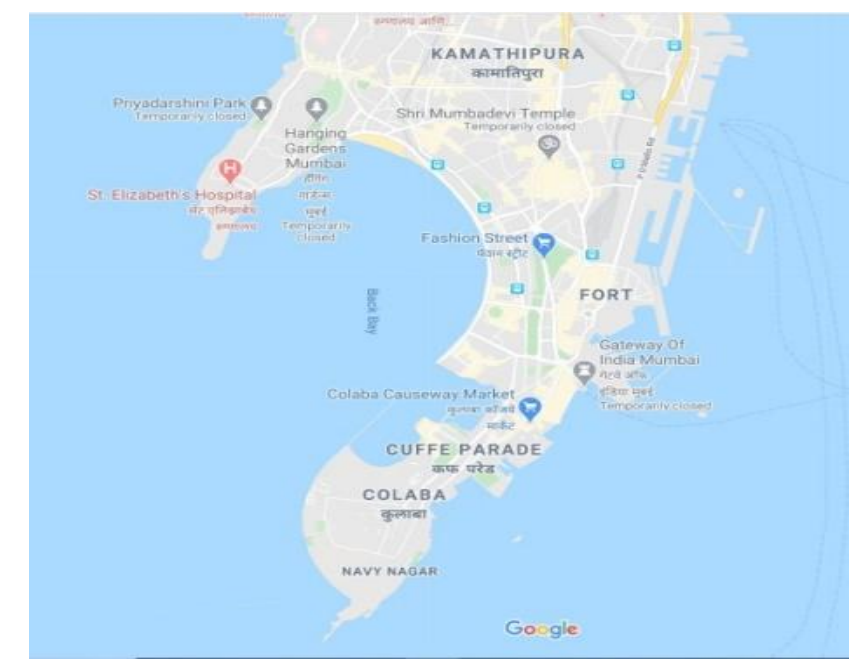

Figure 2 Topographic Map of Project Region (Source: googlemaps/india)

To overcome this, it chose vertical development and today it is a home for around 2.3 crore people thus making it the financial capital of India. Mumbai is the aroma of fresh breeze, twinkling with lights, high rises, wider roads, modern people and on and on. It has answers if you are in for it. That's what makes it "City of Dreams". Everything about this city is beautiful. People come here to make it a point to have a glimpse of the promenade. I guess, this is how most of the tourist's identity it. This inspired us to build a 3D model of Mumbai city. The study area is located at Nariman Point. It is the business hub of Mumbai city and located in south Mumbai, at the end of Marine Drive. The study area covers $1.23 \mathrm{sq} . \mathrm{km}$. and its coordinates are $18.926^{\circ} \mathrm{N}$ and $72.823^{\circ} \mathrm{E}$ on the map. For the initial stage a small portion of Mumbai city, Nariman Point was selected as a subject for the analysis. Its well-known identity and being the business hub of India are the factors of selection. We call it as 3D Mumbai City.

\section{METHODOLOGY}

The 3D Mumbai city required different types of data. The main source of information is the topographic map and the aerial photographs of the case study area. It provided the geographic location which provides the details of its position on the globe, its terrain features such as administrative boundaries, buildings, contour, land use, roads, rivers etc. The photographs provided in-depth details as compared with the maps. Sometimes a couple of photographs are used to determine the building footprints. Figure 3 displays a closer view of building foot 
prints. A digital representation of a land surface is generated using the topography maps and the orthophoto.

This lets you mark the $\mathrm{X}$ and $\mathrm{Y}$ axis of building footprints whereas the height or the elevation information of building is collected using the multiple pictures of the region. The photographs let you design a model authentic and true to photos. These pictures were captured using a standard digital camera.

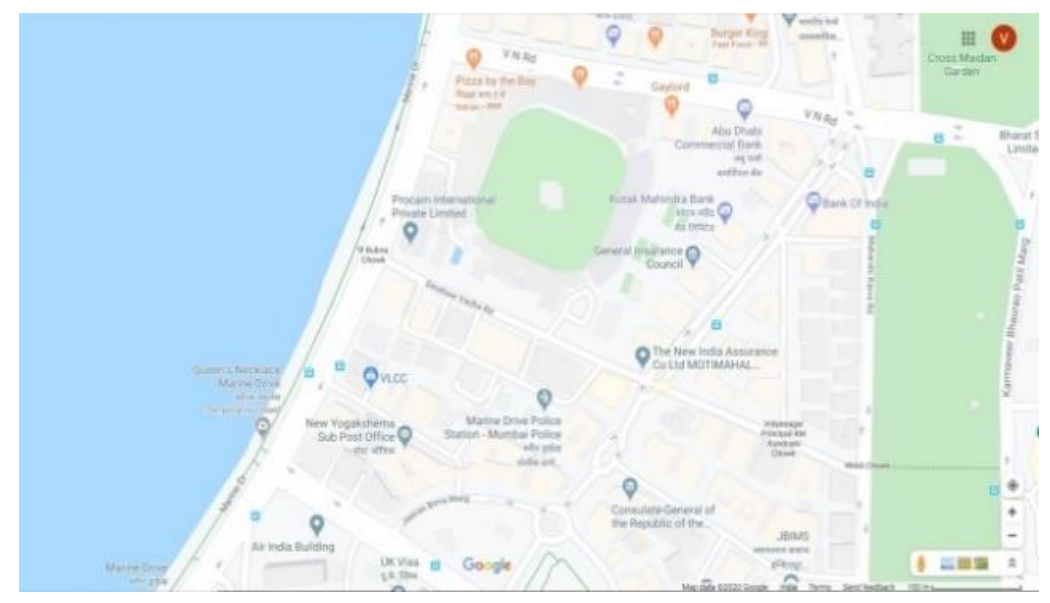

Figure 3 A closer view of the building footprints collected from topography map of our project region Mumbai city.

(Source: googlemaps/india)

Google Earth, Sketchup Pro, Adobe Photoshop and AutoCAD were extensively used to develop the base of the 3D Mumbai City. Sketchup Pro was used in the 3D drafting of buildings and to give them the textures. 3D Studio Max was also used in this project development (e.g. landscaping, ponds, traffic signage, etc.).

The modeling technique used in this project is presented by the workflow scheme (Figure 4).

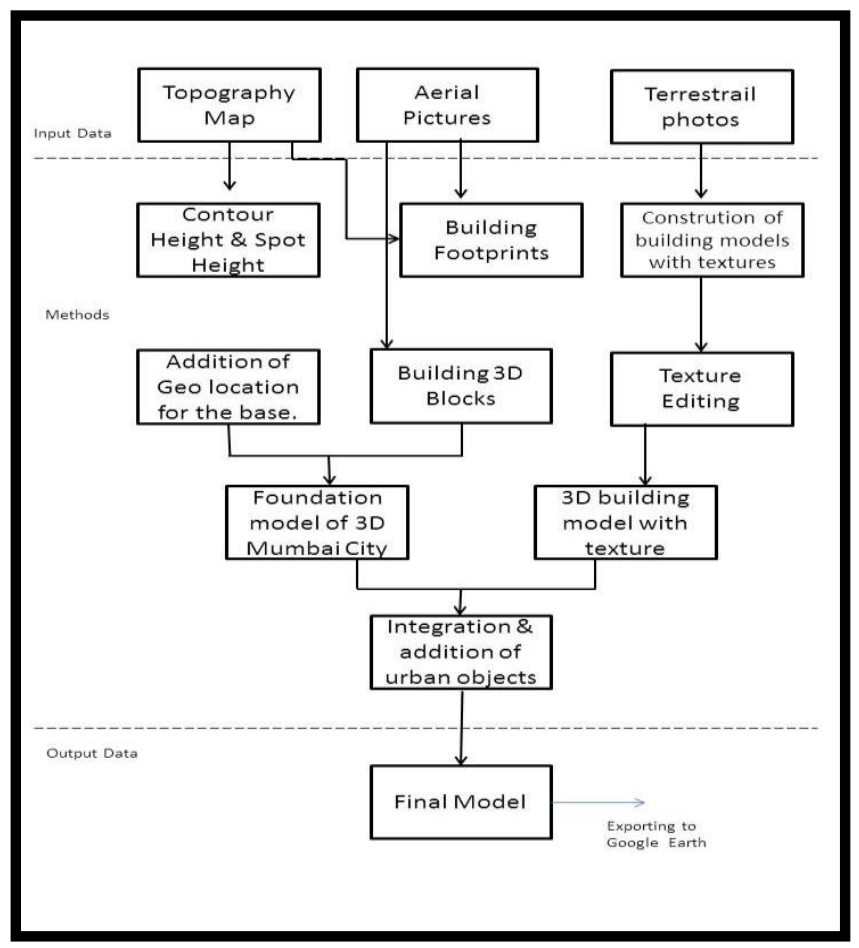

Figure 4 The Modeling Process Flowchart used for this project. 


\section{RESULT \& DISCUSSION}

\subsection{D Model Creation}

The site selection is done using Google Earth and the pictures clicked are used to study the region. The region selected from the maps is now geo-located, having a physical location.

The further step is adjusting the line of axes with the structure or building. The next step is building a 3D block on the map area selected. The result is shown in Figure 5.

The buildings are categorized as per the height derived from the aerial photograph and topographic maps of the project area and then they are merged to create the foundation of 3D Mumbai City. (Figure 6)

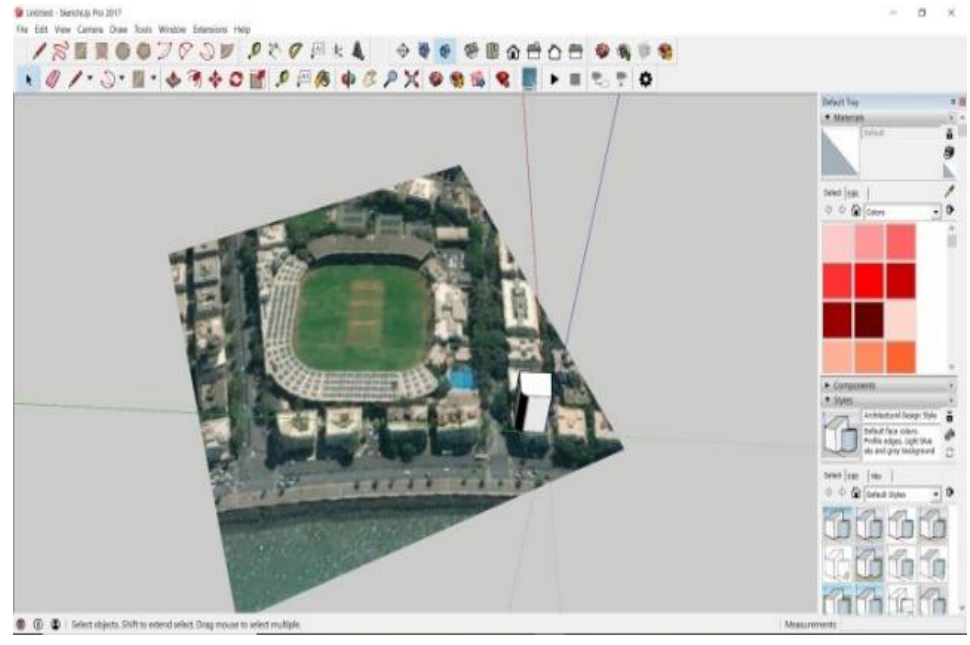

Figure 5 Building of 3D blocks on the foot prints for the creation of 3D Mumbai city.

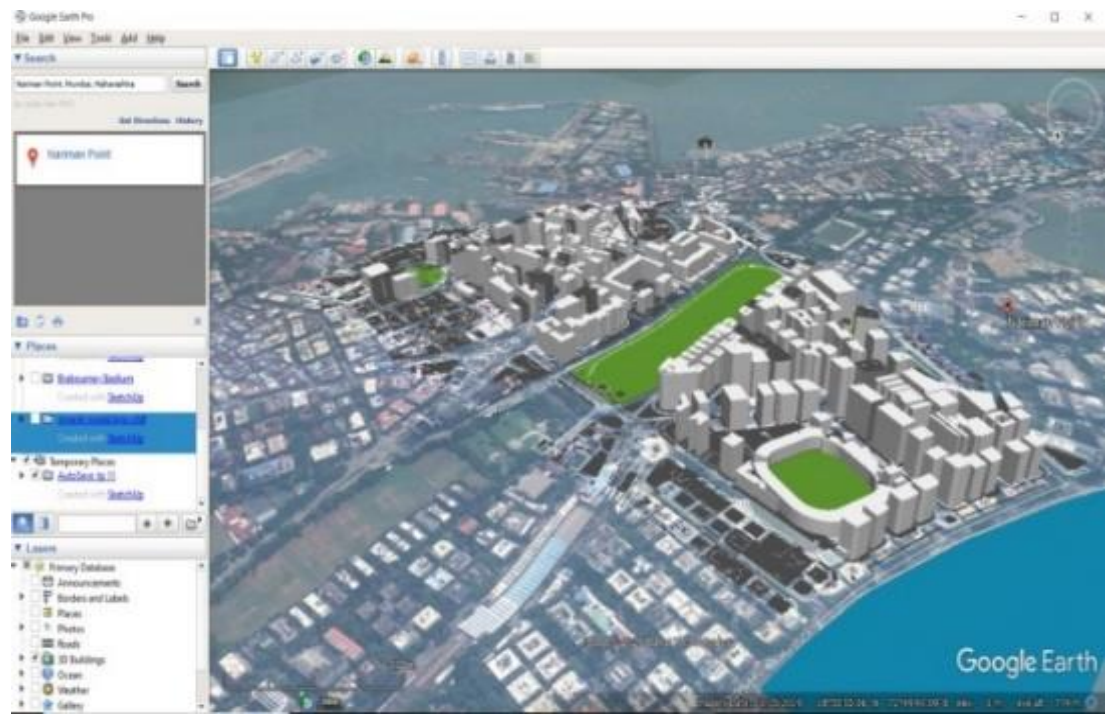

Figure 6 The 3D Mumbai City view on Google Earth

\subsection{Height Map of Project Region}

This 3D city model helped in the creation of the building height plan which classifies the buildings as per their height (Figure 5.1.3). The buildings are classified on the basis of the number of stories. Upon analysis, it has been observed that the maximum number of buildings existing at the project location are having 4 to 6 stories which accounts to nearly $59 \%$ of total 
buildings, while the minimum number of buildings observed is having 10 stories or more which accounts to only $1 \%$. This is because maximum buildings depict the architecture which were built long back with a maximum height of 5 to 6 floors only. There are greater chances of redevelopment of old buildings in our project area and constructing them having all the amenities incorporated in them making most of the use of the land available.

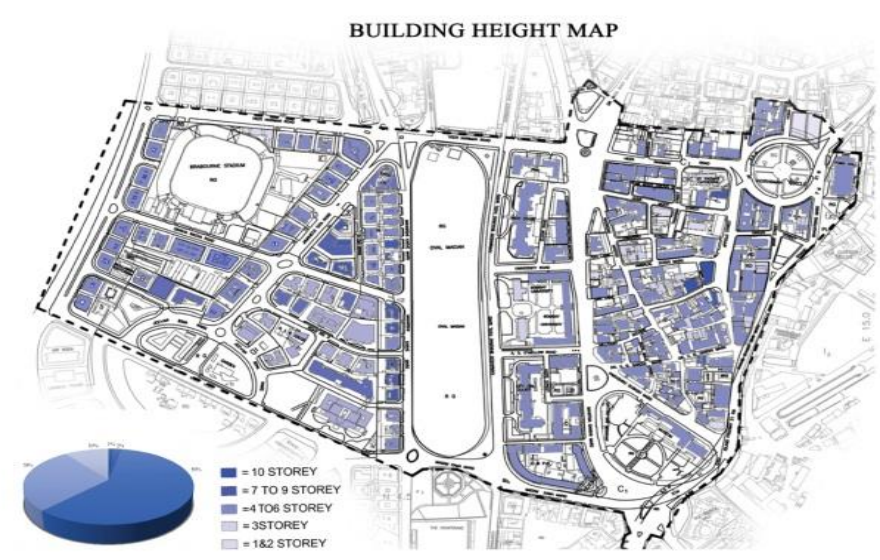

Figure 7 The derived building height plan of project area.

\subsection{Assessment of Urban Utilities: Land Use}

The 3D city model helped to prepare the Floor Space Index or F.S.I. plan of the study region. It classifies the region based on the FSI consumed. The FSI used for the taxation purpose by the government bodies. The maximum development has consumed FSI between 1 and 1.99 comprising $60 \%$ of the total area whereas only $5 \%$ of the development has consumed FSI of 4 and above (Figure 8).

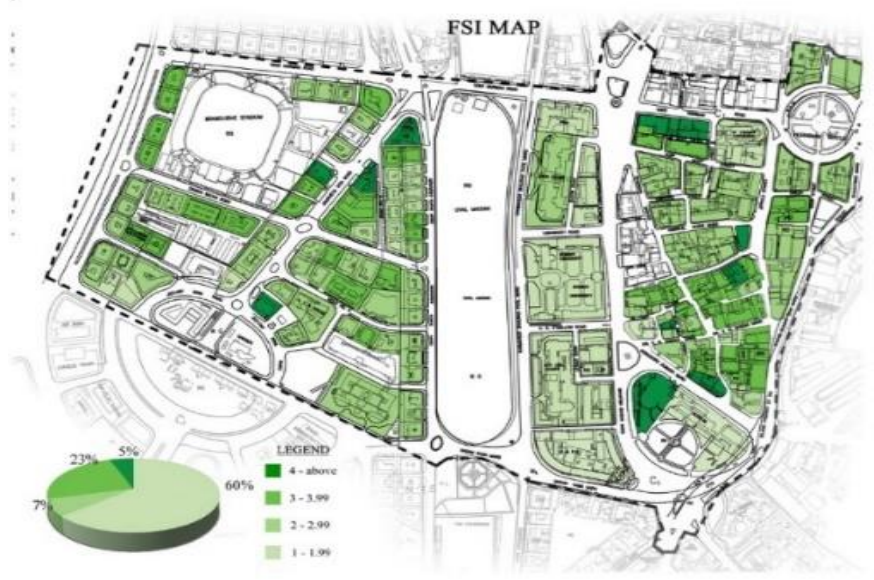

Figure 8 The derived FSI map of project area.

The classification of the city into different zones is possible with its help. New possibilities can be worked out after the visual analysis. The land-based features can be understood using it. The details and visibility is totally depended on the image quality used during the rendering and the scale. It helps in the analysis of the open spaces available in the region. We found out the region has around $40 \%$ of open spaces while $60 \%$ is used for the development. With this we can formulate there can be provisions made for future expansions (Figure 10) 


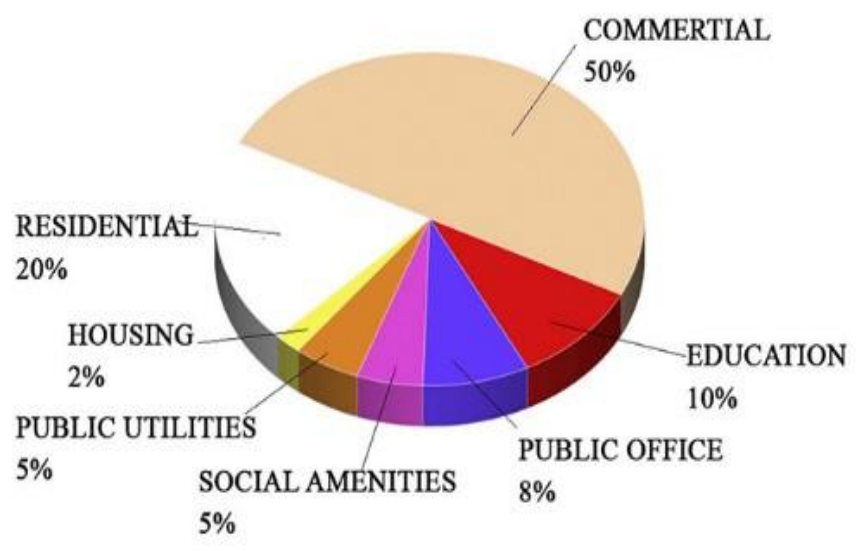

Figure 9 The derived classifications of the project area.

The 3D model of the city helped in the classification of the region. The classification is done according to building usage. Since Nariman Point is the business hub of the Mumbai city, commercial spaces have acquired $50 \%$ of the total space whereas the residential spaces occupy only $20 \%$ of the total spaces. The education premises occupy $10 \%$ of the total space and the public offices are spread across $8 \%$ of the total space. The results are shown with the help of Pie diagram in Figure 9.

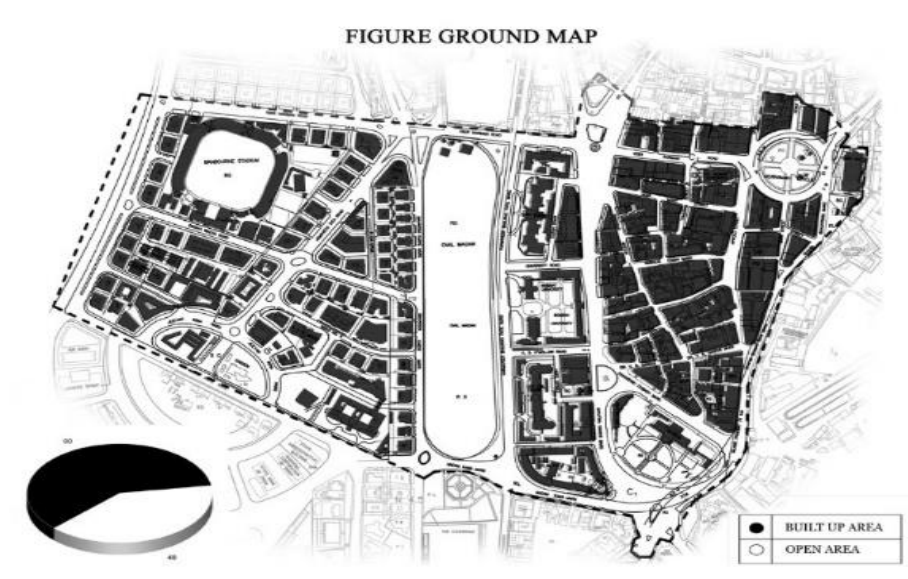

Figure 10 The derived ground map of project area

\subsection{Reconstruction of Heritage Buildings}

The architecture of Mumbai city remains from the Colonial era. It is a perfect mixture of Gothic, Victorian, Art Deco, Indo-Saracenic and contemporary architectural styles. Mumbai bags the second position in the world for having the number of Art Deco Style buildings, while Miami holds the first place. This gave us the inspiration to reconstruct the Landmark structure of Nariman Point "The Soona Mahal Building". The reconstruction of the heritage building was performed as per the methodology described above. This will enable the study of the heritage structures of Mumbai city. The preservation and maintenance works can be worked out easily. The results are shown in Figure 11. 


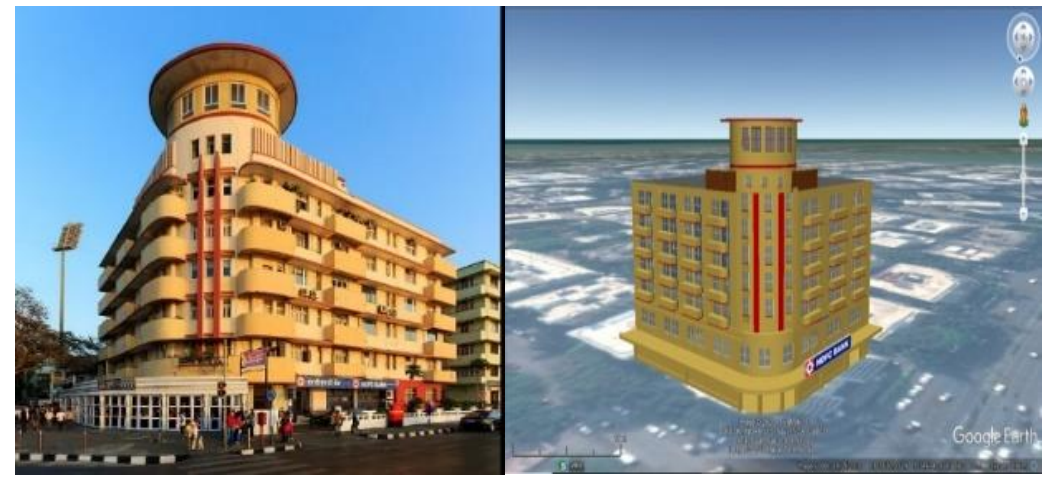

Figure 11 The picture of Soona Mahal, Building (Left) and 3D model of Soona Mahal, added into Google Earth (Right).

Public interest and understanding of the heritage art deco buildings can be promoted via 3D graphics and image files, showing a relationship between them and their neighbourhood (Figure 12).

One of the most difficult tasks is to reconstruct a photo textured building model using terrestrial images clicked from various positions. The building having normal geometry shapes are easy to create while building having complex geometry designs such as the oval, rectilinear shapes, takes a maximum amount of time.

In some cases, we have to edit the images because of some obstructing elements such as parked cars, trees, bushes, electric poles, etc. covering the main object thus blocking the view. The editing is done by using software such as Adobe Photoshop.

Additions of landscape objects such as bus stops, street lamps, trees and traffic signboards will give a real-time view to the 3D Mumbai City. The 3D modeling software Sketchup Pro is used to get the final result.

This will allow users to understand the land-based aspects. The visuals totally depend upon the image quality and the scale of the map. The high-resolution maps provide many reliable and accurate data when compared to the traditional maps.

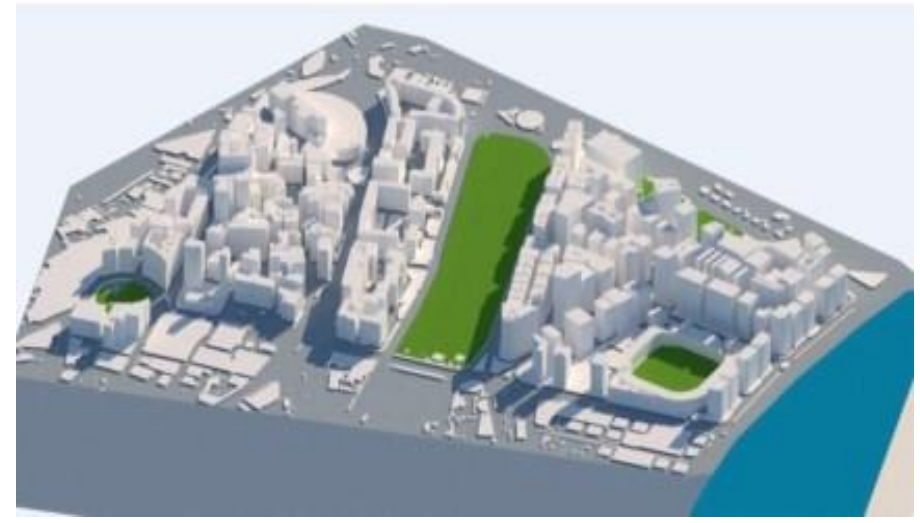

Figure 12 Image showing perspective view of project area

\section{CONCLUSION}

The study region has a maximum commercial establishments when compared to the residential buildings. It also made clear, all the buildings had a common purpose initially which was segregated later. There is a need to plan the space for more residential projects in our project region. An urgent need is to decongest the roads and carry out a proper 
maintenance of the pedestrian movement tracks. The parking lots are not sufficient for the today's usage and also during the future expansion.

The study for preservation and maintenance works of the heritage structures can be worked out easily. Visuals are important for planning, landscaping to find the most appropriate location of projects for the development of the city or town. This 3D city model helps you know the aesthetic aspects of study area. Accepting alternative development layouts are now possible as the perspective of the project can be visualized. Sensitive zones can be developed easily.

A general impression of project on the city's landscape can be visualized as seen in the figures. Site selection for the projects which are not yet finalized can be easily done since the model portrays the project's significance well before its execution. This model will be bringing a new vision to urban planning and design standards. These visuals enable us to find a better perspective of the development plan or to find its alternatives. The planning of an ideal city should not be too much chaotic or too much ordered. The nature should have an organized complexity and must possess variety and order having a compact size and visible life and keeping it local into characteristic. The land providing goods and services for mankind should be protected.

Future work is to create 3D model of large urban cities and add them on the Google Earth because it will lead to number of opportunities of creating different form of analysis and will let the planner's to study them.

\section{ACKNOWLEDGEMENTS}

The authors gratefully acknowledge the support and courtesy of the Pillai HOC College of Engineering and Technology, Rasayani, for the research related works presented in this paper.

\section{COMPLIANCE WITH ETHICS GUIDELINES}

Mr. Shrenik Dinesh Shah, Mr. Raju Narwade and Mr. Karthik Nagarajan declare that they have no conflict of interest or financial conflicts to disclose.

\section{REFERENCES}

[1] Anthopoulos, L.G.; Vakali, A. Urban planning and smart cities: Interrelations and reciprocities. In The Future Internet Assembly 2012: From Promises to Reality, Aalborg, Denmark, 10-11 May 2012; Springer: Heidelberg/Berlin, Germany, 2012; pp. 178-189.

[2] Batty M. Chapman D. Evans S. Haklay M. Küppers S. Shiode N.Smith A. \& Torrens P.M., (2001) Visualizing the city: communicating urban design to planners and decisionmakers. In: Brail R. \& Klosterman R. (eds), Planning Support Systems. ESRI Press and Center Urban Policy Research, Rutgers University Press, New Brunswick, NJ (in print).

[3] Bourdakis, V. (1997) Making Sense of the City, Centre for advanced Studies in Architecture (CASA), University of Bath, UK

[4] Bourdakis, V. and Day, A. (1997) A VRML Model of Bath in R. Coyne, M. Ramsar, J.Lee \& K.Zreik (eds) Design3and the Net, europIA Productions, pp.13-22

[5] Chen M, Lin H, Hu M, He L, Zhang C. Real-geographic-scenario-based virtual social environments: integrating geography with social research. Environ Plan. 2013; 40(6):1103-21. doi:10.1068/b38160

[6] Dodge, M., Doyle. S., Smith. A. \& Fleetwood, S. (1998) Towards the Virtual City: VR \& Internet GIS for Urban Planning, Birkbeck College, UK.

[7] "Google Earth". Google. Retrieved March 15, 2020. 
[8] Hillier, B. The city as a socio-technical system: A spatial reformulation in the light of the levels problem and the parallel problem. In Digital Urban Modeling and Simulation; Arisona, S.M., Aschwanden, G., Halatsch, J., Wonka, P., Eds.; Springer: Heidelberg/Berlin, Germany, 2012; Volume 242, pp. 24-48.

[9] Institute of Environmental Assessment and the Landscape Institute (IEATLI) (1995). Guidelines for Landscape and Visual Impact Assessment. First Edition. London: E\&FN SPON, and imprint of Chapman \& Hall.

[10] Isikdag, U.; Zlatanova, S. Towards defining a framework for automatic generation of buildings in CityGML using building Information Models. In 3D Geo-Information Sciences; Lee, J., Zlatanova, S., Eds.; Springer: Heidelberg/Berlin, Germany, 2009; pp. 79-96.

[11] Kolbe, T.H. Representing and exchanging 3D city models with City GML. In 3D GeoInformation Sciences; Lee, J., Zlatanova, S., Eds.; Springer: Heidelberg/Berlin, Germany, 2009; pp. 15-31.

[12] M. Sinning-Meister, A. Gruen, H. Dan (1996). 3D City models for CAAD - supported analysis and design of Urban Areas", Photogrammetry and Remote Sensing, 51, No. 4, August 1996, (196-208)

[13] Qiang, W., Hua, X. (2004). "Study on 3D geological modeling and visualization. Science in China", Series D: Earth Science, 34, 54-60.

[14] Rahimian,F. P., \& Ibrahim, R.(2011).Impacts of VR 3D sketching onno vice designers' spatial cognition in collaborative conceptual architectural design. Design Studies, 32(3), 255-291.

[15] Randolph, J. (2011). Environmental land use planning and management. Washington DC: Island Press. 